\title{
Physical performance of patients with numerous psychosomatic complaints suggestive of hyperventilation
}

\author{
T. Troosters*, A. Verstraete*, K. Ramon*, R. Schepers**, R. Gosselink*, \\ M. Decramer**, K.P. Van de Woestijne**
}

Physical performance of patients with numerous psychosomatic complaints suggestive of hyperventilation. T. Troosters, A. Verstraete, K. Ramon, R. Schepers, R. Gosselink, M. Decramer, K.P. Van de Woestijne. C) ERS Journals Ltd 1999.

ABSTRACT: In some patients exercise induces numerous complaints which cannot be attributed to an organic disorder, and which are suggestive of hyperventilation. The study was designed to investigate in this type of patient: 1) exercise capacity and muscle force; 2) breathing pattern and symptoms during maximal exercise and recovery; 3 ) relationships between symptoms and breathing pattern.

Twenty-four patients were compared with 20 healthy subjects. They performed a maximal incremental cycle ergometer test and peripheral and respiratory muscle strength were measured.

Patients tended to have a decreased exercise capacity and presented with moderately reduced muscle strength. At comparable minute ventilation, breathing frequency was higher (mean: 24 versus 21 per minute) and tidal volume smaller (mean: 1.42 versus $1.67 \mathrm{~L})$. End-tidal partial pressure of carbon dioxide $\left(P \mathrm{ET}, \mathrm{CO}_{2}\right)$ was not significantly different. A significant relation was observed between $\mathrm{PET}_{2} \mathrm{CO}_{2}$ and respiratory frequency during recovery in patients, suggesting a reduced flexibility of the ventilatory response to exercise. In patients respiratory complaints and paresthesias were weakly correlated to $P$ ET, $\mathrm{CO}_{2}$ at moderate exercise.

It is suggested that the physical deconditioning observed in those patients is rather a consequence than a cause of the response to exercise. The link between symptoms and breathing pattern might be explained by a psychological conditioning process. Eur Respir J 1999; 14: 1314-1319.

Patients with numerous complaints on exercise, not readily explained by somatic disorders have been described now and again since 1871 [1-5]. The term "effort syndrome" was coined for this condition by LEwIS [2] and linked later on to the hyperventilation syndrome (HVS) [3]. However, the attribution of the symptoms to hyperventilation was questioned in 1941 by Wood [4], on the basis of the fact that respiratory alcalosis was not observed during effort. A reduced tolerance to exercise in those patients, documented by FrIEDMAN [5], was confirmed more recently by KInNULA and SoviJÄRvi [6]. These investigators noticed abnormally high ventilatory equivalents for $\mathrm{O}_{2}\left(V^{\prime} \mathrm{E} / V^{\prime} \mathrm{O}_{2}\right)$ and for $\mathrm{CO}_{2}\left(V^{\prime} \mathrm{E} / V^{\prime} \mathrm{CO}_{2}\right)$ during exercise, inversely related to arterial $\mathrm{CO}_{2}$ partial pressure. In addition, higher values of $V^{\prime} \mathrm{E} / V^{\prime} \mathrm{CO}_{2}$ during mild exercise $(40-50 \mathrm{~W})$ reliably discriminated patients from healthy subjects.

The evolution of end-tidal $\mathrm{CO}_{2}$ partial pressure (PET, $\mathrm{CO}_{2}$ ) was studied during exercise by CHAMBERs et al. [7] in a large group of patients referred for the assessment of chest pain. Seventy percent of the patients with symptoms of breathlessness suggestive of hyperventilation and without electrocardiographic ST depression during exercise demonstrated hypocapnia $\left(P \mathrm{ET}, \mathrm{CO}_{2}<4 \mathrm{kPa}\right)$ during both recovery and exercise. Fifty per cent of these patients failed to show the absence of the normal rise of $P \mathrm{ET}, \mathrm{CO}_{2}$
*Depts of Respiratory Rehabilitation and **Dept of Pneumology, University Hospitals, K.U. Leuven and Faculty of Physical Education and Physiotherapy, K.U. Leuven, Leuven, Belgium.

Correspondence: K.P. Van de Woestijne Laboratory of Pneumology

U.Z.Gasthuisberg B-3000 Leuven Belgium Fax: 3316343124

Keywords: Conditioning exercise capacity

hyperventilation syndrome

hypocapnia

muscle strength

ventilatory pattern

Received: May 51998

Accepted after revision June 31999 during the first minute of exercise (initial hyperventilation). These findings were uncommon in patients with ST depression or in healthy control subjects. Among the patients with normal electrocardiogram during exercise, $25 \%$ had high anxiety or depression scores. Breathing frequency during exercise was significantly higher in those patients [8].

The present study was designed to investigate the exercise capacity and muscle strength of a group of patients referred to the laboratory because of complaints suggestive of HVS and to study the relation between hypocapnia, breathing pattern, and symptoms during and following an exercise test.

\section{Materials and methods}

Subjects

The patients had been referred to the laboratory because they presented complaints which could not be explained by a somatic disease and which were suggestive of the HVS. An organic disorder had been excluded previously on the basis of thorough clinical, functional and laboratory examinations. HVS was suspected because of the high scores on the Nijmegen Questionnaire for daily life complaints [9] and the reproduction of the complaints partly or totally, 
by voluntary hyperventilation ( 3 min of hyperventilation, at a frequency of $60 \cdot \mathrm{min}^{-1}$, resulting in a reduction of $P$ ET, $\mathrm{CO}_{2}$ by half or more). Immediately following this manoeuvre, forced expiratory volume in one second (FEV1) and vital capacity were measured. Hyperventilation did not elicit any noticeable bronchoconstriction. Thirteen males and 11 females were included. Five subjects were on sick leave because of their symptoms, while the others were professionally active at the moment of the study. According to the criteria of the Diagnostic and Statistical Manual of Mental Disorders (DSM-IV), 20 subjects suffered from anxiety disorders (panic disorder in eight; generalized anxiety disorder in four; agoraphobia in four; anxiety disorder not otherwise specified in two; social phobia (with dysthymia) in two), four from a somatoform disorder (undifferentiated somatoform disorder in two; pain disorder (one with hypochondria) in two). One patient was an endurance athlete, (an amateur cyclist, who suddenly experienced intense choking during a bicycle trip in the mountains. Shortly before, the patient had been ill with severe bronchitis, requiring antibiotics. Because the patient blamed the effort for permanently damaging their lungs, they didn't dare to exercise any more.) while others were sedentary. The healthy subjects (11 males, 9 females) were recruited outside the hospital. They were professionally active; none was involved in competition sports. As for the patients, smoking habits were not a criterium for recruitment. Table 1 groups some biometrical and functional data of the investigated subjects, as well as the scores of the Nijmegen Questionnaire (16 daily life complaints, scored as 0: never, 1: rarely, 2: sometimes, 3: often, 4: very often) and of the state and trait anxiety inventory (STAI) of SPIELBERGER et al. [10]. The latter scores were significantly higher in patients. A further grouping of the items of the Nijmegen questionnaire under complaints of central nervous system, paresthesias, anxiety, respiratory and cardiac complaints, showed that the summed scores were significantly $(p \leq 0.001)$ higher in patients for each group of complaints.

Table 1. - Biometric data and scores of complaints and anxiety level

\begin{tabular}{|c|c|c|}
\hline & Healthy subjects & Patients \\
\hline Sex M/F & $11 / 9$ & $13 / 11$ \\
\hline Age yrs & $42.7 \pm 9.7(21-58)$ & $41.4 \pm 9.8(20-61)$ \\
\hline Height $\mathrm{cm}$ & $171 \pm 8.7(158-184)$ & $169 \pm 7.8(158-185)$ \\
\hline Weight $\mathrm{kg}$ & $71.3 \pm 12.2(53-105)$ & $71.1 \pm 11.4(51-93)$ \\
\hline FEV1 L & $3.9 \pm 0.8$ & $3.6 \pm 1.0$ \\
\hline predicted $\%$ & $115 \pm 15$ & $110 \pm 26$ \\
\hline FVC L & $5.1 \pm 1.1$ & $4.6 \pm 1.1$ \\
\hline predicted \% & $125 \pm 14$ & $115 \pm 20$ \\
\hline MVV L $\cdot \min ^{-1}$ & $156 \pm 32$ & $147 \pm 46$ \\
\hline $\begin{array}{l}\text { Nijmegen } \\
\text { Questionnaire }\end{array}$ & $7.9 \pm 5.2$ & $30.3 \pm 9.7^{*}$ \\
\hline STAI-state & $31.8 \pm 8.2$ & $48.8 \pm 14.1^{*}$ \\
\hline STAI-trait & $30.5 \pm 5.8$ & $47.7 \pm 11.2 *$ \\
\hline
\end{tabular}

Data are presented as mean \pm SD with range in parentheses. *: $\mathrm{p} \leq 0.001$. M: male; F: female; FEV1: forced expiratory volume in one second; FVC: forced vital capacity; MVV: maximum voluntary ventilation; STAI: state and trait anxiety inventory. The predicted values are based on those from QUANJER [11].

\section{Procedure}

The subjects first completed the Nijmegen Questionnaire and STAI-state and trait inventories. FEV1, forced vital capacity (FVC) and maximal voluntary ventilation (MVV) were measured by means of a pneumotachograph. For MVV, the subjects were requested to breathe as quickly and deeply as possible during $12 \mathrm{~s}$. The exercise test was performed on a bicycle ergometer (Ergo-line 900; Mijnhardt bv., Bunnik, The Netherlands). The subject breathed through a face mask coupled to a low resistance breathing valve (Hans Rudolph; Kansas City, MO, USA) separating inspiratory and expiratory lines of an open breathing circuit. Following a period of rest during $2 \mathrm{~min}$, exercise was initiated at $20 \mathrm{~W}$ and increased every 2 min by $30 \mathrm{~W}$. The cycling frequency was kept constant at 60 revolutions per minute. The subject was coached to achieve the highest possible effort. Exercise was followed by a 6 min period of recovery. During the first minute of the recovery the subject was asked to continue cycling without loading. During the exercise test, minute ventilation $\left(V^{\prime} \mathrm{E}\right)$, respiratory frequency $(f)$, partitioned into inspiratory $(t \mathrm{I})$ and expiratory $(t \mathrm{E})$ times, and tidal volume $(V \mathrm{~T})$ were recorded via a pneumotachograph inserted in the expiratory line. Fractional concentration of $\mathrm{CO}_{2}$ and $\mathrm{O}_{2}$ was sampled continuously from the mask (Rudolph Mask 7910; Hans Rudolph) and determined respectively by means of an infra-red cell and Zirconium analyser. Oxygen consumption $\left(V^{\prime} \mathrm{O}_{2}\right)$ and $\mathrm{CO}_{2}$ production $\left(V^{\prime} \mathrm{CO}_{2}\right)$, respiratory exchange ratio $(\mathrm{R})$ and ventilatory equivalents for $\mathrm{O}_{2}$ and $\mathrm{CO}_{2}\left(V^{\prime} \mathrm{E} / V^{\prime} \mathrm{CO}_{2}\right)$ were computed on line, using $10 \mathrm{~s}$ averages of recorded ventilatory and gas concentration data (Partn air 5400; Medisoft, Dinant, Belgium). The oxygen saturation and electrocardiogram were recorded throughout the test. Following the exercise test and 6 min recovery phase, the subjects completed a questionnaire concerning 31 possible symptoms during and following exercise. The complaints were grouped, according to a principal components analysis performed previously [12], into 9 factors, the 5 most important ones being: complaints of central nervous system (dizziness, blurred vision, fainting), respiratory complaints (dyspnoea, air hunger, discomfort in the chest), paresthesias and stiffness of the extremities, anxiety and cardiac complaints (palpitations). The intensity of the complaints was evaluated by a 5 point scale from 0 (no complaint) to 4 (very intense). The scores of the complaint factors were obtained by summing the individual scores and by dividing the sums by the number of individuals and the numbers of complaints per factor.

Before or after the exercise test, quadriceps force [13], handgrip strength [14], and maximal inspiratory and expiratory pressures [15] were determined.

\section{Results}

\section{Muscle force}

Table 2 shows that except for maximal expiratory pressure, respiratory and peripheral muscle force was moderately but statistically reduced in patients. MVV was not significantly influenced.

\section{Exercise performance and recovery}

The values of ventilation, $V^{\prime} \mathrm{O}_{2}$ and $P \mathrm{ET}, \mathrm{CO}_{2}$ at rest, measured on the bicycle prior to the exercise, were similar 
Table 2. - Muscular force, maximal respiratory pressures, maximal work load and oxygen consumption

\begin{tabular}{|c|c|c|}
\hline & $\begin{array}{l}\text { Healthy } \\
\text { subjects }\end{array}$ & Patients \\
\hline $\begin{array}{l}\text { Quadriceps force } \mathrm{Nm}^{\S} \\
\text { predicted } \%{ }^{\#}\end{array}$ & $\begin{array}{l}190.5 \pm 47.5 \\
100.6 \pm 11.9\end{array}$ & $\begin{array}{c}151.9 \pm 43.3 \\
80.4 \pm 14.6^{* *}\end{array}$ \\
\hline $\begin{array}{l}\text { Handgrip strength } \mathrm{N}^{\S} \\
\text { predicted } \%\end{array}$ & $\begin{array}{c}523 \pm 141 \\
123.1 \pm 19.7\end{array}$ & $\begin{array}{c}440 \pm 99 * * * \\
100.3 \pm 17.1 * *\end{array}$ \\
\hline $\begin{array}{l}\text { Maximal inspiratory pressure } \\
\mathrm{kPa}^{\S} \\
\text { predicted } \%^{+}\end{array}$ & $-10.9 \pm 2.8$ & $-9.0 \pm 2.8 * * *$ \\
\hline $\begin{array}{l}\text { Maximal expiratory pressure } \\
\mathrm{kPa}^{\S}\end{array}$ & $17.9 \pm 5.7$ & $16.6 \pm 5.8$ \\
\hline Maximal work load $\mathrm{W}^{\# \#}$ & $\begin{array}{l}101.1 \pm 25.5 \\
206 \pm 52\end{array}$ & $\begin{array}{l}92.1 \pm 21.5 \\
179 \pm 47\end{array}$ \\
\hline $\begin{array}{l}\text { Maximal oxygen consumption } \\
\text { L.min } \\
\text { predicted } \%{ }^{-+}\end{array}$ & $3.05 \pm 0.99$ & $2.58 \pm 0.80$ \\
\hline
\end{tabular}

Data are presented as mean \pm SD. $* *: p \leq 0.001 ; * * *: p \leq 0.05 .{ }^{\S}$ : taken from 20 healthy subjects and 16 patients; ${ }^{\text {: }}$ predicted values are based on those by DECRAMER et al. [13]; : based on those by Mathiowetz et al. [14]; ${ }^{+}$: based on those by Rochester and ARORA [16]; \#\#: taken from 20 healthy subjects and 24 patients; ${ }^{++}$: based on those by Jones et al. [17].

in healthy subjects and in patients. Maximal work load and $V^{\prime} \mathrm{O}_{2}$ peak tended to be lower in patients $(\mathrm{p}=0.08$ and 0.09 respectively) (table 2). When one very well trained patient $\left(V^{\prime} \mathrm{O}_{2}\right.$ peak: $4.25 \mathrm{~L} \cdot \mathrm{min}^{-1}(213 \%$ predicted) at $260 \mathrm{~W})$ was left out the differences became statistically significant $(\mathrm{p}=0.04$ and 0.05 respectively). Similar findings were observed when $V^{\prime} \mathrm{O}_{2}$ peak was expressed in percentage of the predicted values $\left(V^{\prime} \mathrm{O}_{2}\right.$, max pred) [17] $(\mathrm{p}=0.10$, but $\mathrm{p}=0.01$ when the trained patient was omitted). In 17 patients $V^{\prime} \mathrm{O}_{2}$ during exercise reached or exceeded $100 \%$ of predicted; in five patients, $V^{\prime} \mathrm{O}_{2}$, max was between 100 and $90 \%$, in two it was, respectively, 69 and $72 \%$ of predicted. Breathing frequency was significantly higher $(\mathrm{p}<0.05)$ in patients than in healthy subjects (fig. 1). This is due to lower values of $t \mathrm{I}(\mathrm{p} \leq 0.05$ or $\leq 0.01)$ and $t \mathrm{E}$ $(\mathrm{p} \leq 0.05)$ (between $50-100 \% V^{\prime} \mathrm{O}_{2}$,max pred). There was a simultaneous reduction of $V \mathrm{~T}$ in patients, statistically significant $(\mathrm{p} \leq 0.05)$ at higher values of $V^{\prime} \mathrm{O}_{2}$, max pred. $V^{\prime} \mathrm{E}, P \mathrm{ET}, \mathrm{CO}_{2}, V^{\prime} \mathrm{CO}_{2}, \mathrm{R}$ and $V^{\prime} \mathrm{E} / V^{\prime} \mathrm{CO}_{2}$ were not significantly different between healthy subjects and patients. In the two patients with the lowest $V^{\prime} \mathrm{O}_{2}$, max, $\mathrm{R}$ increased more rapidly with work load $\left(\mathrm{R}>1.0\right.$ at $50 \% V^{\prime} \mathrm{O}_{2}$, $\max$ pred). The patients on sick leave presented the lowest $P \mathrm{ET}, \mathrm{CO}_{2}$ and highest $V^{\prime} \mathrm{E} / V^{\prime} \mathrm{CO}_{2}$ values of all patients, whereas $V^{\prime} \mathrm{O}_{2}$, max were within normal range $(90-168 \%$ of expected).

Data concerning recovery following exercise were available from at least $70 \% V^{\prime} \mathrm{O}_{2}$,max pred in 20 patients. These data were not available in four patients either because $70 \% V^{\prime} \mathrm{O}_{2}$, max was not reached during exercise, or within $<10 \mathrm{~s}$ following cessation of exercise. In the early recovery, all values were similar between patients and controls with the exception of $\mathrm{R}$, which was significantly $(\mathrm{p}<0.05)$ higher in healthy subjects. In contrast, in the further course of the recovery, $f$ was significantly higher, $t \mathrm{I}$, $t \mathrm{E}$, and $V \mathrm{~T}$ significantly less in patients. $P \mathrm{ET}, \mathrm{CO}_{2}$ was not significantly different between patients and healthy subjects (fig. 1).

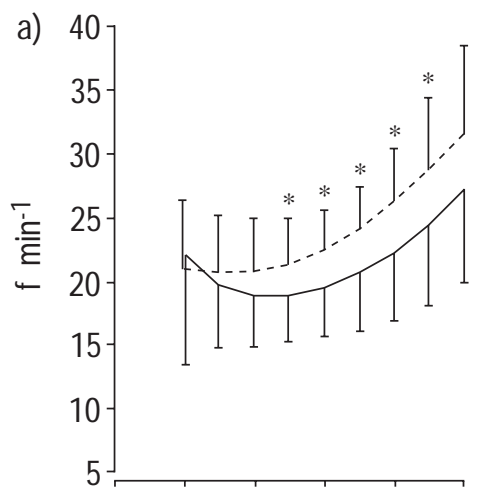

b)
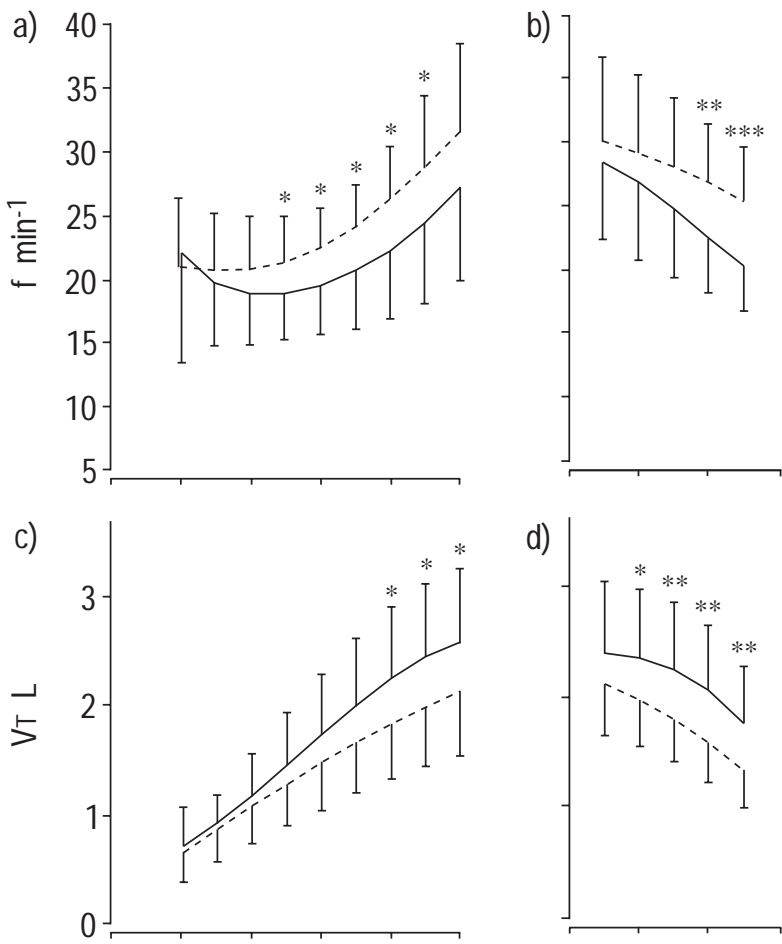

d)
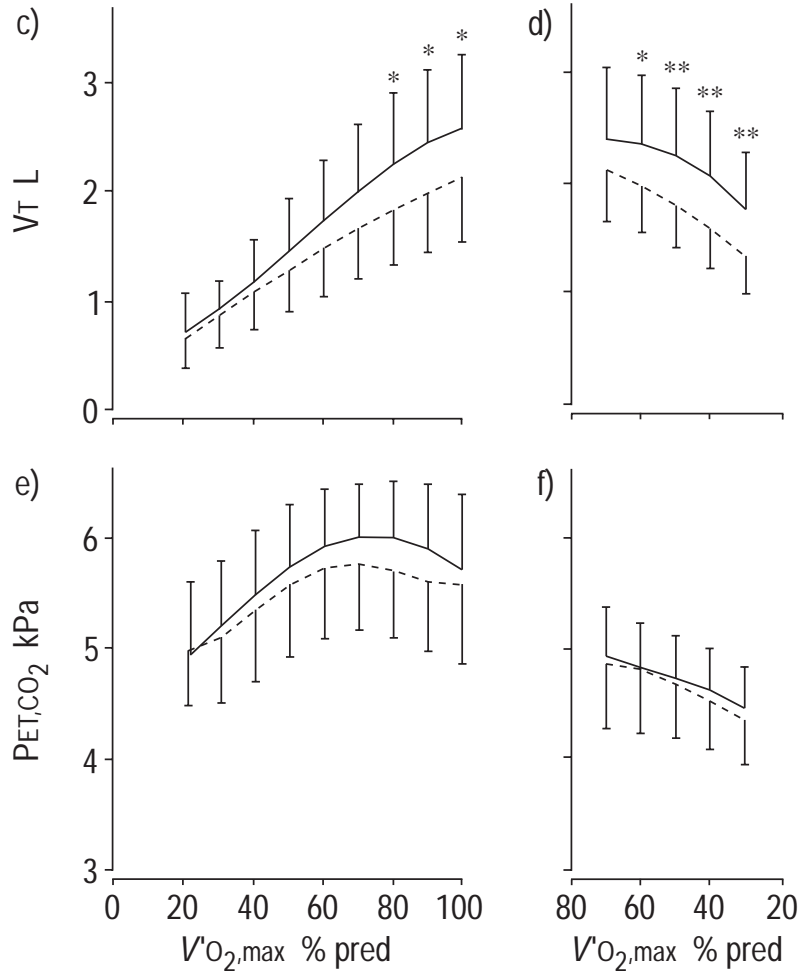

Fig. 1. - Mean values and standard deviations during exercise (a, $\mathrm{c}$ and e) and recovery (b, d and f) of breathing frequency $(f)$, tidal volume $(V \mathrm{~T})$, and end-tidal partial pressure of $\mathrm{CO}_{2}\left(\mathrm{PET}_{\mathrm{CO}}\right)$, as a function of $\mathrm{O}_{2}$ consumption expressed in percentage of predicted maximal consumption $\left(V^{\prime} \mathrm{O}_{2}\right.$, max \% predicted), in a group of 20 control subjects (- - ) and of the 17 patients (out of 24) who reached $100 \%$ of $V^{\prime} \mathrm{O}_{2}$, max predicted. Adding the patients who did not reach $100 \% V^{\prime} \mathrm{O}_{2}$, max predicted yielded similar mean values of $f, V \mathrm{~T}$ and $P$ ET, $\mathrm{CO}_{2}$.

The correlations between breathing variables $(t \mathrm{I}, t \mathrm{E}, V \mathrm{~T})$ and $P$ ET, $\mathrm{CO}_{2}$ at 70 and $30 \%$ of $V^{\prime} \mathrm{O}_{2}$, max pred during exercise did not reach statistical significance. During recovery, however, strong correlations between $P \mathrm{ET}, \mathrm{CO}_{2}$ and $t \mathrm{E}(\mathrm{r}=0.67, \mathrm{p}=0.001)$, and particularly $t \mathrm{I}$ (fig. 2) were observed, only in patients.

\section{Complaints during exercise and recovery}

Patients had significantly more complaints than healthy subjects (table 3). The highest scores (more than twice the mean scores of all patients) were reached by the patients 

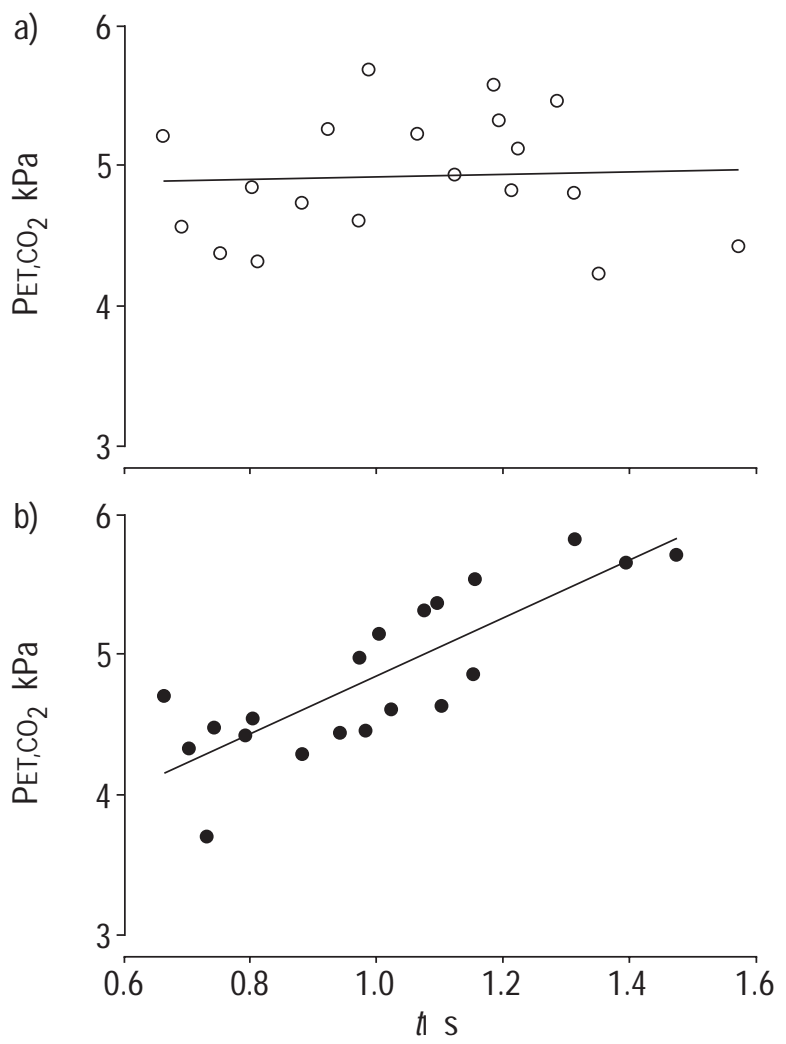

Fig. 2. - Correlation between end-tidal partial pressure of $\mathrm{CO}_{2}$ $\left(P \mathrm{ET}, \mathrm{CO}_{2}\right)$ and inspiratory time $(t \mathrm{I})$ at the onset of recovery from exercise $\left(70 \% V^{\prime} \mathrm{O}_{2}, \max \right)$ in control subjects $(\mathrm{a} ; \bigcirc)$ and patients $(\mathrm{b} ; \mathbf{O})$. The regression lines are shown. The correlations are not significantly modified when the influence of sex, age and body height are taken into account (a: $r=0.07, p=0.76 ; b: r=0.83 ; p=0.0001$ ).

on sick leave. Only respiratory complaints and paresthesias in the extremities during exercise were significantly $(\mathrm{p}<0.01)$ correlated with $P$ ET, $\mathrm{CO}_{2}$, (at 30 and $70 \%$ $V^{\prime} \mathrm{O}_{2}$,max pred) and with breathing frequency (at $30 \%$ $V^{\prime} \mathrm{O}_{2}$, max pred) in patients, not in healthy subjects.

Table 3. - Scores of intensity of complaints during exercise and recovery in healthy subjects and patients

\begin{tabular}{lcc}
\hline & Healthy subjects & Patients \\
\hline Central nervous system & & \\
$\quad$ Exercise & $0.02 \pm 0.05$ & $0.66 \pm 0.89^{*}$ \\
$\quad$ Recovery & $0.03 \pm 0.12$ & $0.75 \pm 1.01^{*}$ \\
Respiratory complaints & $0.25 \pm 0.34$ & $0.80 \pm 0.78^{*}$ \\
$\quad$ Exercise & $0.06 \pm 0.16$ & $0.41 \pm 0.51^{*}$ \\
$\quad \begin{array}{l}\text { Recovery } \\
\text { Paresthesias in extremities }\end{array}$ & $0.05 \pm 0.13$ & $0.33 \pm 0.52^{*}$ \\
$\quad$ Exercise & $0.08 \pm 0.20$ & $0.54 \pm 0.68^{*}$ \\
$\quad$ Recovery & $0.23 \pm 0.42$ & $0.70 \pm 0.94^{* *}$ \\
Anxiety & $0.02 \pm 0.08$ & $0.69 \pm 1.10^{* *}$ \\
$\quad$ Exercise & & \\
$\quad$ Recovery & $0.75 \pm 0.76$ & $1.13 \pm 1.10$ \\
Cardiac complaints & $0.85 \pm 0.90$ & $1.15 \pm 1.15$ \\
$\quad \begin{array}{l}\text { Exercise } \\
\text { Recovery }\end{array}$ & & \\
\hline $\begin{array}{l}\text { Data are presented as mean } \pm \text { SD. Unpaired t-test: *: } \mathrm{p} \leq 0.01 ; * * \\
\text { p } \leq 0.05 .\end{array}$ &
\end{tabular}

\section{Discussion}

On average, the present group of patients was characterized by a moderate reduction of muscle respiratory and peripheral force. Similarly, FolgERING and SNIK [18] documented a $10 \%$ reduction of maximal handgrip force in patients with HVS. The maximal work load and $V^{\prime} \mathrm{O}_{2}$ peak were slightly reduced (at the limit of statistical significance). Most patients (17/24) were able to develop a maximal $V^{\prime} \mathrm{O}_{2}$ which was $\geq 100 \%$ of the predicted values [17]. These results are in keeping with the observations of others $[5,6]$. Since most patients complained of fatigue resulting in a spontaneous reduction of their level of physical activity in daily life, these findings might be attributed to physical deconditioning.

Besides a reduced physical performance, another factor appears to characterize the group of patients. Respiratory frequency during exercise was higher (due to a decrease of both $t \mathrm{E}$ and $t \mathrm{I}$ ) and $V \mathrm{~T}$ lower than in healthy subjects. This pattern is not determined by the level of physical training: it was also observed in the few patients with supramaximal values of $V^{\prime} \mathrm{O}_{2}$,max. A similar ventilatory pattern was also present during the recovery period: $t \mathrm{E}, t \mathrm{I}$, and $V \mathrm{~T}$ were relatively smaller. This is in keeping with an earlier study of COHEN and White [19], who documented in military personnel with "effort syndrome", a disproportionate rise in breathing frequency during exercise and recovery (accompanied in their subjects by an increase in $\left.V^{\prime} \mathrm{E}\right)$. Similarly, BAss et al. [8] noticed that in a group of patients investigated for the assessment of chest pain, patients with higher anxiety scores had a significantly higher mean breathing frequency during exercise.

$P$ ET, $\mathrm{CO}_{2}$ was not significantly reduced in our group of patients. Only one patient was frankly hyperventilating $\left(P\right.$ ET, $\left.\mathrm{CO}_{2}<4 \mathrm{kPa}\right)$ during exercise as well as during recovery. This patient also had a high ventilatory equivalent for $\mathrm{CO}_{2}$ and is similar to the subjects studied by KINNULA and SoviJARvi [6] who were probably more severely disabled than the current patients. Indeed, these subjects were selected on the basis of low values of arterial partial pressure of $\mathrm{CO}_{2}\left(\mathrm{PCO}_{2}\right)(<4.7 \mathrm{kPa})$ and alkalosis $(\mathrm{pH}>$ 7.45 ) at rest. Though the equivalents for $\mathrm{CO}_{2}$ were, on average, slightly higher in the current patients than in control subjects, the differences were not significantly different. In patients, who were incapacitated because of their complaints, equivalents for $\mathrm{CO}_{2}$ were higher and $P$ ET, $\mathrm{CO}_{2}$ values were lower during exercise than in the other patients. These patients had also markedly more complaints.

Because the intensity of the exercise test was limited by the individual exercise tolerance, the duration of the tests varied among the subjects. To compare the ventilatory data between healthy subjects and patients, fixed levels of $V^{\prime} \mathrm{O}_{2}$ (in percentage of $V^{\prime} \mathrm{O}_{2}$, max pred) were used. It could be pondered as to whether this procedure does not introduce a bias in the comparison. Indeed, a given value of $V^{\prime} \mathrm{O}_{2}$ during exercise (or recovery) might be achieved at very different times in the course of the test. In fact, the duration between the onset of exercise (or recovery) and the moment that a given value of $V^{\prime} \mathrm{O}_{2}$ was achieved did not differ significantly between the patients and healthy control subjects. For instance, $65 \% V^{\prime} \mathrm{O}_{2}$, max pred was reached, on average, in $6.6 \mathrm{~min}$ in healthy, and $7.0 \mathrm{~min}$ in patients $(\mathrm{p}=0.73)$ after the onset of exercise. During recovery, 30\% 
$V^{\prime} \mathrm{O}_{2}$,max pred was reached after $2.2 \mathrm{~min}$ in healthy, and 2.7 min in patients $(\mathrm{p}=0.12)$ following cessation of exercise. It is likely, therefore, that the time course of the adaptation to exercise was similar in the two groups of subjects.

Do these findings throw light on the mechanisms of the complaints reported by the patients? The largest differences in breathing pattern compared to healthy subjects were observed during the early minutes of recovery. A disproportionate increase in breathing frequency was the most apparent finding. It is known that the first minutes of recovery following heavy work are characterized by a further increase of the metabolic acidosis produced by heavy exercise, accompanied by a reduction of arterial and $P$ ET, $\mathrm{CO}_{2}[20,21]$. In the present study, the reduction of $P$ ET, $\mathrm{CO}_{2}$ during the first minutes of recovery was, on average, similar in patients and in healthy subjects. However, in contrast to healthy subjects, the values of $P \mathrm{ET}, \mathrm{CO}_{2}$ in patients were closely linked to respiratory frequency, mainly to $t \mathrm{I}$ (fig. 2). Obviously, when a given value of hypocapnia is imposed (here by the level of metabolic acidosis), healthy subjects have a choice between an increase in $V \mathrm{~T}$ or in breathing frequency, whereas patients mainly rely on an increase in frequency, particularly a decrease in $t \mathrm{I}$.

A similar selective use of breathing frequency in order to increase $V^{\prime} E$ was also observed in patients with HVS and with anxiety disorders after voluntary hyperventilation [22]. The latter is followed in those patients by an increased poststimulus potentiation with delayed recovery of PET, $\mathrm{CO}_{2}$. HAN et al. [22] showed that in HVS patients and those with anxiety disorders the reduction of $P \mathrm{ET}, \mathrm{CO}_{2}$ was achieved by keeping a high breathing frequency, rather than a large $V \mathrm{~T}$. (It was only in younger men $(<28$ yrs of age) that recovery of $P \mathrm{ET}, \mathrm{CO}_{2}$ was delayed via $V \mathrm{~T}$. In the present study, only one male patient was aged $<28$ yrs).

Apparently, when ventilation is stimulated by an increase in ventilatory drive (e.g. during exercise, or because of acidosis or poststimulus potentiation), this type of patient resorts to an increase in frequency rather than in $V \mathrm{~T}$ to increase ventilation. This peculiar breathing pattern is accompanied by a number of subjective symptoms, mainly related to breathing and to the central and peripheral nervous system. These symptoms are not necessarily accompanied by hyperventilation. Indeed, frank hypocapnia was exceptional in the present study and the correlations between complaints and $P \mathrm{ET}, \mathrm{CO}_{2}$ were weak. This suggests that hypocapnia is a consequence rather than a cause of the symptoms [23].

It has been proposed that the tendency to report numerous and intense complaints during exercise is the result of a psychological conditioning process [24], for instance following a previous chest disease or an experience focusing the attention on the respiratory system [25]. The symptoms occurring during intense effort are misinterpreted and lead the subject to believe that they are suffering from a life threatening condition. This corresponds precisely to the history reported spontaneously by one of the current patients. Conditioning of breathing, realized experimentally in healthy subjects, has shown that the type of symptoms reported by the patients in the present study are easily conditioned and that the process is accompanied by changes in ventilatory pattern, primarily an increase in breathing frequency [26].
It seems therefore, that the sequence of events responsible for symptoms and breathing abnormalities during exercise in this group of patients is as follows. Firstly, a psychological conditioning process generated by, or linked to exercise, might be the origin of the many symptoms, i.e. the high anxiety level and a peculiar breathing pattern. The symptoms, when marked, result in a tendency to hyperventilate during and following exercise, with production of new symptoms (paresthesias, dizziness). The learned response is then reinforced by every new trial to exercise. Finally, the occurrence of symptoms with the slightest exertion leads to a reduction of physical activity and an ensuing deterioration of exercise tolerance.

\section{References}

1. Da Costa JM. On irritable heart; a clinical study of functional cardiac disorder and its consequences. $\mathrm{Am} \mathrm{J}$ Med Sci 1871; 61: 17-52.

2. Lewis T. Report on neurocirculatory asthenia and its management. Military Surgeon 1918; 42: 409-426.

3. Soley MH, Shock NW. The etiology of effort syndrome. Am J Med Sci 1928; 196: 840-851.

4. Wood P. Da Costa's syndrome (or effort syndrome). BMJ 1941; i: 805-811.

5. Friedman M. Functional cardiovascular disease. Baltimore, USA, Williams and Wilkins, 1947; pp. 266.

6. Kinnula VL, Sovijärvi ARA. Elevated ventilatory equivalents during exercise in patients with hyperventilation syndrome. Respiration 1993; 60: 273-278.

7. Chambers JB, Kiff PJ, Gardner WN, Jackson G, Bass C. Value of measuring end tidal partial pressure of carbon dioxide as an adjunct to treadmill exercise testing. $B M J$ 1988; 296: 1281-1285.

8. Bass C, Chambers JB, Kiff P, Cooper D, Gardner WN. Panic anxiety and hyperventilation in patients with chest pain. A controlled study. Quat J Med 1988; 69: 949-959.

9. Van Dixhoorn J, Duivenvoorden HJ. Efficacy of Nijmegen questionnaire in recognition of the hyperventilation syndrome. J Psychosom Res 1985; 29: 199-206.

10. Spielberger CD, Gorsuch RL, Luchene RE. The StateTrait Anxiety Inventory (STAI) test manual for form X. Palo Alto, CA, USA, Consulting Psychologist Press, 1970.

11. Quanjer Ph. Standardized lung function testing. Bull Eur Physiopath Respir 1983; 19(Suppl. 5): 1-91.

12. Han JN, Stegen K, Schepers R, Van den Bergh O, Van de Woestijne KP. Subjective symptoms and breathing pattern at rest and following hyperventilation in anxiety and somatoform disorders. J Psychosom Res 1998; 45: 519 532.

13. Decramer M, Lacquet LM, Fagard R, Rogiers P. Corticosteroids contribute to muscle weakness in chronic airflow obstruction. Am J Respir Crit Care Med 1995; 152: 2021-2031.

14. Mathiowetz V, Dove M, Kashman N, Rogers S. Grip and pinch strength normative data for adults. Arch Phys Med Rehabil 1985; 66: 69-72.

15. Black LF, Hyatt RE. Maximal respiratory pressures: normal values and relationships to age and sex. Am Rev Respir Dis 1969; 9: 696-702.

16. Rochester D, Arora NS. Respiratory muscle failure. Med Clin North Am 1983; 67: 573-598. 
17. Jones NL, Makrides L, Hitchcock C, Chypchar T, McCartney N. Normal standards for an incremental progressive cycle ergometer test. Am Rev Respir Dis 1985; 131: 700-708.

18. Folgering H, Snik A. Hyperventilation syndrome and muscle fatigue. J Psychosom Res 1988; 32: 165-171.

19. Cohen ME, White PD. Studies of breathing, pulmonary ventilation and subjective awareness of shortness of breath (dyspnea) in neurocirculatory asthenia, effort syndrome, anxiety neurosis. J Clin Invest 1947; 26: 520-529.

20. Stringer W, Casaburi R, Wasserman K. Acid-base regulation during exercise and recovery in humans. $J$ Appl Physiol 1992; 72: 954-961.

21. O'Neill AV, Johnson DC. Transition from exercise to rest. Ventilatory and arterial blood gas responses. Chest 1991; 99: 1145-1150.
22. Han JN, Stegen K, Simkens K, et al. Unsteadiness of breathing in patients with hyperventilation syndrome and anxiety disorders. Eur Respir $J$ 1997; 10: 167-176.

23. Hornsveld HK, Garssen B, Fiedeldij Dop MJC, van Spiegel PI, de Haes JCJM. Double-blind placebo-controlled study of the hyerventilation provocation test and the validity of the hyperventilation syndrome. Lancet 1996; 348: 154-158.

24. Wood P. Aetiology of Da Costa's syndrome. BMJ 1941; i: 845-851.

25. Ferguson A, Addington WW, Gaensler EA. Dyspnea and bronchospasm from inappropriate post exercise hyperventilation. Ann Intern Med 1969; 71: 1063-1072.

26. Van den Bergh O, Kempynck PJ, Van de Woestijne KP, Baeyens F, Eelen P. Respiratory learning and somatic complaints: a conditioning approach using $\mathrm{CO}_{2}$-enriched air inhalation. Behav Res Ther 1995; 5: 517-527. 